\title{
Bareback Equestrian Trauma: Pubic Symphysiolysis and Abdominal Arterial Hemorrhage
}

\author{
David Spelt ${ }^{\#}$, Herman Frima ${ }^{\#}$, Lijckle van der Laan ${ }^{\#}$ \\ Department of Surgery, Amphia Hospital, Breda, Netherlands \\ E-mail:d.s.spelt@gmail.com,hfrima@gmail.com,lvanderlaan@amphia.nl \\ Received April 11, 2011; accepted July 15, 2011; accepted September 6, 2011
}

\begin{abstract}
Pubic symphysiolysis and retroperitoneal arterial vessel rupture after bareback horse riding is a rare traumatic combination. We report a case of a 59-year-old man who experienced severe pubic, abdominal and lower back pain due to a bounce after a asynchronous rhythm of horseback riding without a saddle. The patient was referred to our Emergency Department because of a suspected ruptured abdominal aortic aneurysm. Computer tomography demonstrated diastasis of the pubic symphysis, active bleeding of a branch of the left internal iliac artery and a massive retroperitoneal haematoma. The arterial bleeding was directly coiled in the emergency setting, the stable pubic symphysiolysis was treated conservatively and the haematoma was surgically drained after three days. Bareback horse riding can lead to a pelvic fracture and severe bleeding leading to haemodynamical instability and life threatening situations. Using proper protective equipment including a saddle to prevent equestrian injury should be emphasized.
\end{abstract}

Keywords: Equestrian, Pubic Symphysiolysis, Hemorrhage, Trauma

\section{Background}

This report describes the case of a 59-year-old man with a type Tile B1 Stage 1 pelvic fracture [1] and rupture of a ventral branch of the left internal iliac artery after bareback horse riding. This traumatic injury after bareback horse riding is a rare feature and a comparable case has only been reported once [2]. Late diagnosis of intra-abdominal hemorrhage can cause severe hypovolemic shock and death, potential functional problems of the gastrointestinal and urogenital tract due to compression and hemorrhagic adhesion or infection of the haematoma. The arterial bleeding of our patient was treated with angiographic coil embolisation by the interventional radiologist [3], the pubic symphysiolysis was treated conservatively and the haematoma was surgically removed three days post trauma. After three weeks of clinical recovery there was an indication for a second laparotomy and removal of remaining haematoma.

\footnotetext{
*Competing interests: The author(s) declare that they have no competing interests.

\#Authors' contribution: All three authors were equally involved in the manuscript design, and collection and interpretation of data. The manuscript was written by all three authors. All authors have read and given final approval of the version to be published and they take responsibility for appropriate portions of the content.
}

\section{Case Presentation}

A General Practitioner (GP) referred a 59-year-old man to our Emergency Department under suspicion of a ruptured abdominal aortic aneurysm. The patient complained of severe lower abdominal pain with radiation to the lower back. In supine position the blood pressure was stable at $125 / 90 \mathrm{mmHg}$ with a solid pulse of $70 \mathrm{BPM}$. But after trying to stand up from the bed the man had collapsed three times. The patient arrived by ambulance at our Emergency Department (ED). He mentioned he had been horseback riding without a saddle that morning. Just before the incident he was riding an asynchronous rhythm and suddenly he landed on the bare back of the horse with excessive force. Immediately he experienced intense pain in the pubic region, the abdomen and successively progressive radiating pain in the left side of the lower back. In a few hours the abdominal pain became unbearable and he consulted his GP. His medical history mentioned severe obstructive pulmonary pathology, spontaneous pneumothorax, primary thrombocytosis, diagnosed many years before the traumatic accident and surgical correction of a right lateral inguinal hernia twenty-six years earlier. His daily medication consisted of budesonide/formoterolfumerate (Symbicort ${ }^{\circledR}$ ) 400/12 mg inspi- 
rator, tiotropium (Spiriva ${ }^{\circledR}$ ) $18 \mathrm{mcg}$ and Aspirin (Acetosal®) $80 \mathrm{mg}$.

On arrival, we saw a very painful man with a blood pressure of 105/65 $\mathrm{mmHg}$, a heart rate of $115 \mathrm{BPM}$ and pulse oximetry indicated a peripheral saturation degree of $99 \%$. A swelling was visible in de midline of the lower abdomen of 8 by $12 \mathrm{~cm}$ diameter with $2 \mathrm{~cm}$ outward protrusion. No bowel sounds were heard, percussion and palpation was very painful in the entire pubic and abdominal region. Intense abdominal muscle resistance was felt. There was no palpable pain over the lumbar spine, the pelvis was stable in all directions, but the patient experienced severe compression pain over the pubic region. Rectal examination was normal. The patient produced normal clear urine and no meatal blood was seen. Pulsations of both femoral arteries were palpable, there was no pulsating abdominal mass. Neurologic examination was normal. Haemoglobin concentration was $6.3 \mathrm{mmol} / \mathrm{L}$ (normal $8.5-11.0 \times 10 \mathrm{E}^{9} / \mathrm{L}$ ), WBC count was $41.6 \times 10 \mathrm{E}^{9} / \mathrm{L}$ (normal $4-10 \times 10 \mathrm{E}^{9} / \mathrm{L}$ ) and thrombocyte count was $1830 \times 10 \mathrm{E} 9 / \mathrm{L}$ (normal $150-400 \times$ $\left.10 \mathrm{E}^{9} / \mathrm{L}\right)$.

Direct computer tomography (CT-scan) of the pelvis and abdomen with early arterial and late venous contrast was performed. This demonstrated diastasis of the symphysis pubis of $11.4 \mathrm{~mm}$ but without posterior lesions, fracture classification Tile B1 Stage 1 [1]. In the midline, ventral in the small pelvis, there was an active blush of the left obturator artery with a massive haematoma $(9 \times$ $10 \times 13 \mathrm{~cm})$ around this bleeding. The SI joint and haematoma are seen in (Figure 1). Angiographic endovascular coil embolisation (Cook, Tornado $\AA$, macro coils 6 and $3 \mathrm{~mm}$ ) of the damaged artery was performed by the interventional radiologist. His haemoglobin level was lowered to $4.6 \mathrm{mmol} / \mathrm{L}$ for which he received two units of packed red blood cells. The patient was admitted at the Intensive Care Unit (ICU) of our hospital for observation of haemodynamical parameters. After one day the patient was transferred to a general surgery nursing unit. The third day he developed pulmonary embolisms and a decrease in haemoglobin level $(5.3 \mathrm{mmo} / \mathrm{L})$. There was an indication to start therapeutic anticoagulant treatment. Therefore a midline laparotomy was performed to remove the haematoma and search for any persisting leakage but no active bleeding was found. During surgery there was absence of significant pelvic instability but evident pubic symphysiolysis. Continuation of bed rest was indicated.

Sixteen days later a new CT-scan was performed because of progressive abdominal pain and decrease of haemoglobin level $(4.7 \mathrm{mmol} / \mathrm{L})$. The scan demonstrated a new haematoma that again was surgically removed without evidence of active bleeding. Seven days later the patient fully recovered and could be dismissed from the ho-

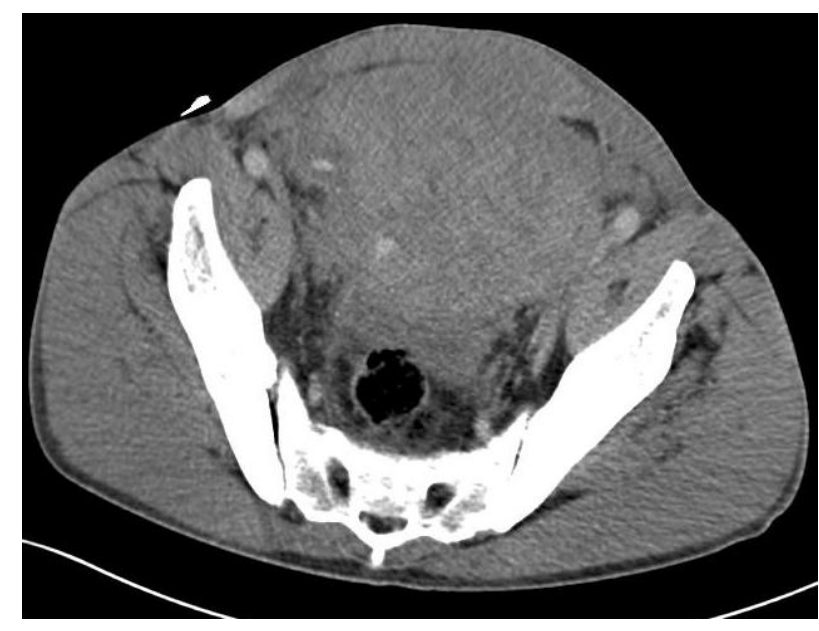

Figure 1. CT scan: normal alignment of the posterior sacroiliac joint with massive retroperitoneal haematoma.

spital. Follow-up at two and six weeks revealed moderate pain in lower abdomen and pubic region but he was fully able to walk and had no genitourinary dysfunction or complaints.

\section{Discussions and Conclusions}

Horseback riding is a common sports activity. But it tends to be more dangerous than motorcycle riding, skiing, automobile racing, football and rugby [4]. One in four to five equestrians will be seriously injured during their riding career $[5,6]$. The combination of height, weight, force, unpredictability of the horse and the riders position makes the latter so vulnerable [4,7]. Serious equestrian injuries are due to falling or being bucked of a horse and most commonly occur at home or at recreational and sporting facilities $[7,8]$. Of this trauma population $11 \%-14 \%$ is admitted for one or more days. Men are less frequently $(34 \%-41 \%)$ involved in non-fatal equestrian injuries. Fractures are diagnosed in $25 \%$ till $32 \%$ of all emergency room visits. $12 \%-30 \%$ of all fractures concern the lower trunk, lumbar spine with or without a fractured pelvis $[5,8]$. In $6.6 \%$ of all fractures it concerns a pelvic fracture.

Although excessive splaying force on the pelvis will first lead to rupture of the symphysis ligament [9], it is not known to be a common type of equestrian injury. A combination of a fracture and haematoma is frequently diagnosed in any type of trauma but pelvic symphysiolysis and arterial bleeding has rarely been documented. So far eight cases of horse saddle-related pelvic injuries are published in English literature. In all of these cases the equestrian used a saddle and the type of injury was bucking of the horse leading to comparable pain sensation $[1,10,11]$. Together with our report eight out of nine patients were male. A reasonable explanation comes from 
the fact that the male pelvic arch is narrower than the female arch and therefore more vulnerable to forced separation by the horses back causing pubic symphysiolysis [1]. Including our report three cases demonstrated accompanying arterial injury with severe complications. But in two patients besides our case there was obvious pelvic instability due to significant widening of the sacroiliac joint $[1,11]$. Presumably during the accident pelvic diastasis was larger than seen during imaging at the hospital. The sacroiliac ligaments of the posterior part of the pelvic ring were intact causing the left and right pubic bones to approach each other again after the impact and symphysiolysis.

We couldn't find review articles that differentiated between equestrians injuries caused by horseback riding with or without a saddle. Both utilization of proper protective equipment and implementation of safety standards are recommended regularly [4-8,12-14]. Adequate usage of a securing saddle is mentioned less frequently [5] although we concern a saddle as a primary prevention safety measure. Without a saddle a rider can't use stirrups that tend to give the equestrian stability and an opportunity to rise up from the saddle. Our patient mentioned he was riding in asynchronous rhythm before he landed very hard on the bare back of the horse. With a securing saddle and stirrups he might have been able to correct this asynchronous rhythm and thereby preventing his severe injury. Usage of a securing saddle should therefore be recommended to all equestrians.

This report describes a male patient with pelvic symphysiolysis and accompanying arterial vessel rupture caused by excessive pelvic forces after an asynchronous rhythm during bareback horse riding. The bleeding in our haemodynamical instable patient was treated with angiographic endovascular coil embolisation and the patient received two packed red blood cells. The pubic symphysiolysis was treated conservatively. A retroperitoneal haematoma was surgically removed. Bareback horse riding can cause pelvic fractures and arterial bleeding leading to a haemodynamically instable equestrian. The relatively low energy of the injury may create a false sense of security; it can be a life threatening situation. Besides the regularly recommended protective equipment in horse riding it should be emphasized to use a securing saddle at all times.

\section{Consent}

Written informed consent was obtained from the patient for publication of this case report and any accompanying images. A copy of the written consent is available for review by the Editor-in-Chief of this journal.

\section{References}

[1] M. Tile, "Pelvic Ring Fractures: Should They Be Fixed?" British Journal of Bone and Joint Surgery, Vol. 70, No. 1, 1988, pp. 1-12.

[2] I. Smith, E. V. Jamieson, J. K. Davey and I. J. McDonald, "Pelvic Diastasis from the Saddle: Not to Be Forgotten," Journal of Trauma, Vol. 53, No. 6, 2002, pp. 1179-1182. doi:10.1097/00005373-200212000-00026

[3] T. G. Walker, "Acute Gastrointestinal Hemorrhage," Techniques in Vascular and Interventional Radiology, Vol. 12, No. 2, 2009, pp. 80-91. doi:10.1053/j.tvir.2009.08.002

[4] J. E. Ball, R. H. Mulloy, I. Datta and A. W. Kirkpatrick, "Ten Years of Major Equestrian injury: are we addressing functional outcomes?" Journal Trauma Management \& Outcomes, Vol. 3, No. 2, 2009, p. 2.

[5] K. A. Thomas, J. L. Annest, J. D. M. Gilchrist, BixbyHammett, "Non-Fatal Horse Related Injuries Treated in Emergency Departments in the United States 20012003," British Journal of Sport Medicine, Vol. 40, No. 7, 2006, pp. 619-626. doi:10.1136/bjsm.2006.025858

[6] J. C. Mayberry, T. E. Pearson, K. J. Wiger, B. S. Diggs, R. J. Mullins, "Equestrian Injury Prevention Efforts Need More Attention to Novice Riders," Journal of Trauma, Vol. 62, No. 3, 2007, pp. 735-739. doi:10.1097/ta.0b013e318031b5d4

[7] E. H. Carrillo, D. Varnagy, S. M. Bragg, J. Levy, K. Riordan, "Traumatic Injuries Associated with Horseback Riding," Scandinavian Journal of Surgery, Vol. 96, No. 1, 2007, pp. 79-82

[8] T. L. Loder, "The Demographics of Equestrian-Related Injuries in the United States: Injury Patters, Orthopedic Specific Injuries, and Avenues for Injury Prevention," Journal of Trauma, Vol. 65, No. 2, 2008, pp. 447-460. doi:10.1097/TA.0b013e31817dac43

[9] R. McRae and M. Esser, "Practical Fracture Treatment," 4th Edition, Churchill Livingstone, Philadelphia, 2002.

[10] A. van Nieuwenhoven, C. van Laarhoven and C. van der Werken, "Pelvic Injuries in Equestrians on Buck Jumping Horses," Journal of Trauma, Vol. 43, No. 5, 1997, pp. 867-868. doi:10.1097/00005373-199711000-00024

[11] M. Flynn, "Disruption of Symphysis Pubis While Horse Riding: A Report of Two Cases," Injury, Vol. 4, No. 4, 1972, pp. 357-358. doi:10.1016/0020-1383(73)90017-X

[12] J. M. Sorli, "Equestrian Injuries: A Five Year Review of Hospital Admissions in British Columbia, Canada," Injury Prevention, Vol. 6, 2000, pp. 59-61.

[13] P. S. Moss, A. Man and M. R. Whitlock, "A Changing Pattern of Injuries to Horse Riders," Emergency Medicine Journal, Vol. 19, No. 5, 2002, pp. 412-414. doi:10.1136/emj.19.5.412

[14] G. L. Christey, D. E. Nelson, F. P. Rivara, S. M. Smith and C. Condie, "Horseback Riding Injuries among children And Young Adults," Journal of Family Practice, Vol. 39, No. 2, 1994, pp. 148-152. 